spent, by passing through the first system of $/$ so severe a form as to cause daily apprehencapillaries; and $I$ am at a loss to imagine sion of a fatal termination, though he is now what reason there can possibly be for sup- happily recovered, and not a vestige of the posing that this weakened force can propel the blood through the second system of capillaries and reins. When we reflect upon the length and tortuosity of the umbilical arteries, the most we ought to expect of the foetal ventricles is, that they propel blood through the capillary terminations of those arteries into the placenta; but to suppose that they, the foetal rentricles, do more than this, that they propel back to the foetus along with that blood an additional quantity through a vein two or three feet in length, and remarkable for its tortuosity, and after all through a second extensive capillary system, the portal plexuses, into the foetal auricles, is, indeed, the very acme of physiological absurdity.

Two othes remarks may be made in opposition to this same notion; first, that before the foetal heart can propel blood it must receive it; and, secondly, that blood does some how or other get propelled through the foetal liver when there is no foetal heart, as is proved by the acardiac foetuses.

To conclude:-As the spleen is the organ by which the blood is propelled through the liver into the heart after birth, so the placenta is simply a temporary spleen by which the blood is propelled through the liver into the heart before birth. In both instances the blood so propelled is a thin or diluted venous blood. That propelled by the spleen is diluted in the splenic and portal veins; and that propelled by the placenta, by having, previous to arriving at this organ, left a part of its solid constituents in the parietes of the uterus.

\title{
ON LARYNGISMUS STRIDULUS.
}

\section{By George A. Rees, Esq., Surgeon, London.}

Having already published a letter in The LANCET on laryngismus stridulus, $I$ hope $I$ shall not be accused of presumption in offering some remarks in reply to Dr. Marshall Hall's communication on that affection, or what he terms stridulous convulsion, in THE $\mathbf{L}_{\text {ANCET for June }} \mathbf{9}$, especially as in my former paper I put forth, and still entertain, what Dr. Hall considers erroneous views of the disease. If further apology be necessary for venturing to differ from so eminent a physiologist, one to whose discoveries I find myself more indebted each day $I$ am in practice, the ample opportunities I have had of observing and studying the malady, must plead my excuse.

The interest $I$ have always felt in the study of the complaint has been painfully increased during the past year, from its occurrence in an infant of my own, and that in

A short description of his symptoms will serve as an introduction to my intended remarks, and this may be given in the form of a case, though anxiety at the time prevented anything like regular note-taking.

H. R., born healthy, had severe diarrhoea during the first fortnight, from which he recovered, and continued well until the age of five months; at this time he was of a fair average size, plump, firm to the touch, and healthy in appearance. He was now shortcoated, and after a few days the nurse complained of his legs being constantly drawn up. On inspection this was found to be the case; they were constantly flexed upon the abdomen, as in cases of abdominal inflammation. This contraction was without rigidity : the legs could be easily straightened, but gradually, on being left to themselves, resumed their bent position. There was at this time no other evidence of disease; the appetite was good, tongue clean, bowels regular, and the infant cheerful. Supposing the position of the legs might be the effects of cold from change of clothing, I ordered long woollen stockings and flaunel next the skin.

After a few days the nurse perceived, early in the morning, the hands and feet slightly contracted, the contraction affecting all the fingers and toes (the carpo-pedal contractions), but lasting only an hour or two, disappearing as the day advanced; at the same time $I$ observed a catch or crow in the inspiration, when the infant awoke in the night, or was disturbed; but this catch was so sudden that it did not interfere with respiration. Together with these symptoms the bowels became confined and disobedient to the action of medicines, the constipation resulting more, apparently, from undue action of the sphincter muscles than from any torpor of the intestinal tube. On inspecting the mouth, the lower incisor teeth were seen just protruding through the gums; they were lanced, and came through in two days. There was not the least appearance of any other teeth advancing, the gums being firm, pallid, uninflamed, not even the mark of a tooth perceptible.

This state of things continued eight or ten days, when the crowing inspiration became much more distinct; the occasional narrowing of the glottis so considerable, as to cause severe dyspnœa; the carpo-pedal contractions more permanent, lasting for days together ; the bowels more confined, and the motions often entirely devoid of bile. To these symptoms supervened in a day or two severe convulsions, produced by the inability to breathe; at first these occurred once, at an interval of two or three days, but became more numerous as the disease progressed, 
The treatment, suggested by medical fricnds, consisted in the application of two leeches to the head, the administration of one grain of calomel every other night, and small doses of assafoctida daily, with the application of cold to the head: the constipation of the bowels was remedied by occasional doses of castor-oil. I was induced also, against the dictates of my own judgment, to lance the gums over the upper incisors once, though not a sign of approaching teeth, nor of any local congestion, was apparent.

These measures, and others which it would be taking up too much space to recount, were tried for a month, and failed to afford any relief; the attacks of dyspnoea became more frequent and more violent; the convulsions more numerous and more severe, not a day passing without one, sometimes two; the patient's strength rapidly declining; and it was determined to try immediate change of air, though the state of the infant forbade any distant removal. He was taken to Peckham Rye; at first the change seemed to promise little benefit, being followed by increased weakness, especially after the fits. On the third day after his journey the exhaustion was so great subsequently to a convulsion, that the nurse considered the infant dying, and in my absence a very intelligent medical practitioner in that neighbourbood, Mr. Stokoe (to whom I am happy to avail myself of this opportunity of returuing my sincere thanks) was called in. He agreed with me in thinking little medicine should be given, and more reliance placed upon the beneficial effects of change of air ; he also recommended the trial of asses' milk. The gums over the upper incisors were again lanced. From that time the infant gradually improved; the fits were less frequent; the hands and feet in a week or eight days became relaxed; the crowing became less distinct each hour; as the patient improved in strength the bowels resumed their regular action; and in a month from the time of removal he was brought home perfectly well, and has so continued to the present time. The upper incisors are not yet come through, the gums are now swelled over them, and there is a prospect of their early eruption; but as the infant continued well, I have not till now thought it necessary to lance them.

This case presents an example of laryngismus stridulus which contrasts well with the one described in my former communication.* In both cases the paroxysms of dyspnoea were very similar, but other symptoms unlike; and I believe the predisposing cause in both the same-the exciting cause totally different. In the case formerly published the attacks proceeding from enlarged thymus, in the one just recited the result of nervous irritation alone.

* See Lancer, No. 925.
The remarks $I$ have to offer will regard chiefly the causes of laryngismus stridulus ; in the greater part of the excellent plan of treatment laid down by Dr. Hall, I think every one of his readers will concur; but there is one point on which I beg to differ from that gentleman, namely, the recommendation to lance the gums when no sign of inflammation is present, nor evidence of approaching teeth. I must enter most respectfully my protest against what I consider unreasonable treatment ; and $I$ confess my sorrow that a practice, which $I$ believe is at present carried too far, should have the sanction of such a name as Marshall Hall's. I cannot believe that lancing the gums, not over isolated teeth, but along the whole extent; not once or twice, but twice a.day; until the repelition of the incision produces ulceration, can be necessary or justifiable, on the supposition of affording relief to a state of sub-inflammation, the existence of which can only be surmised, since none of the sigus of inflammation, neither heat, redness, nor swelling are present. Dr. Hall states that his case may be regarded as presenting " a fair test and criterion of the efficacy of the remedial measures adopted;" but if any reliance can be placed upon the event of a single case, I would point to the one recited above, to show that Dr. Hall's patient might have done equally well under his excellent general treatment without such severe scarification of the gums.

With regard to the cause of laryngismus stridulus, there can be little doubt of the correctness of Dr. Hall's statement, that the predisposing cause, the disposition to this disease, consists in a peculiar susceptibility of the excito-motor property of the nervous system; and I believe in many cases the complaint is excited in subjects so disposed by those sources of irritation and excitement which Dr. Hall has recounted-dentition, indigestible food, \&c., where no organic change, either in the thymus gland or other structure is present; but I feel equally convinced, in other cases the affection is the result of organic change, just as epilepsy may be present from temporary functional derangement at one time, and at another may be a symptom of morbid changes in the brain or its investing membranes.

My experience leads me to state that either of the following changes of structure, enlargement of the cervical glands, hypertrophy of the thymus gland, deformity of the chest from disease of the lungs, may give rise to laryngismus stridulus; and perhaps to these should be added inflammation of the brain : but I cannot decide whether this may be the cause, or whether where it is present it is an effect of the malady. The diffidence I feel in giving an opinion in opposition to Dr. Hall would be greater than it is if, in naming these lesions as causes of laryngismus stridulus, I merely expressed my own 
notions on the subject; but $I$ am adding concurrent testimony to statements made by other and abler members of the profession.

Enlargement of the cervical glands was considered a cause of laryngismus stridulus by the late Dr. Hugh Ley, who supposed that the paroxysms of choking were excited by the pressure of the deeper glands exerted on the recurrent nerves; and in his work (the best on the disease in our language) he has published plates, showing the post-mortem appearances in some fatal cases which he dissected, in which the recurrent nerves were so imbedded in these morbid glands, that it appears impossible they should have performed their functions without obstruction. He also quotes a case cited by Dr. Rush, of a man who suffered from similar paroxysms, one of which proved fatal, in whom after death a small tumour was found in the neck, pressing on the recurrent nerve. I have opened children who have died of this malady, in whom the chief morbid appearance was enlargement of the deep cervical and bronchial glands, and I attributed to them the disease.

Hypertrophy of the Thymus Gland.-That this is a frequent cause of the disease was stated by Dr. Kopp, and his statement is so commonly believed among the Germans, that the affection goes by the name of thymic asthma; but Dr. Hall considers this hypertrophy as the effect, not the cause, of the convulsive efforts of the malady, and adds, "If we carry our views to the congestion of the brain, and bear in mind the effect of the convulsive effort on the thymus gland and face, we shall see the great importance of adopting measures which may relieve the congested encephalon." Dr. Hall then mentions that he has seen the thyroid gland become and remain enlarged " in like manner after the efforts of severe and protracted parturition." Now that the thyroid gland or body, since it bears not the most distant resemblance to a gland, a highly vascular organ, supplied by two ample arteries from the main branches ascending to the head, a body so liable to participate in any general plethora of the system, that in some females it enlarges at each catamenial period. That such a body should, from the violent straining efforts of labour, become and remain enlarged, I can readily believe, but cannot allow any analogy to be instituted between such a state and hypertrophy of the thymus gland. No parity of reasoning can be applied to two structures so entirely different: the thymus is, to all intents and purposes, a conglomerate gland; for Dr. Hall's argument to have any weight, it would be neces. sary for him to adduce instances where the parotid or submaxillary glands had become enlarged from any temporary excitement or cerebral congestion. Moreover, it is impossible for the thymus gland to sympathise very intimately with congestion of the face or head, inasmuch as the supply of blood is derived from a totally different source. The thymus is almost wholly supplied from the internal mammary; in some cases a very small branch comes from the superior thyroid, but this is as often wanting. For these reasons I must still believe that enlargement of the thymus cannot be the effect of laryngismus stridulus, but that where the predisposition to the complaint exists in the nervous system, hypertrophy of that gland may and does cause the affection.

That the disease, if dependent upon change of structure, must be irremediable, is another point on which I must join issue with Dr. Hall. If we consider the probable physiology of the thymus, if it be the grand manufactory of chyle during the later months of foetal and the earlier months of infant existence, $I$ think it will not be difficult to trace to a cause the abnormal enlargement of the gland, while we are directed to a plan of treatment likely to prove successful in removing it. May it not be dependent upon some error in the process of assimilation carried on in the digestive tube after birth? If chylification go on properly in the intestines, the gland is no longer required, and therefore becomes gradually absorbed; but if that process fail it remains, and its unnatural action causes it to enlarge. In this way the beneficial effects of change of air, warm clothing, well-regulated diet, \&c., may be explained.

Deformity of the Chest from Disease of the Lungs.-Mr. Snow was the first who mentioned that in the deformity of the chest mentioned by me as dependent upon disease of the lungs (which deformity is accompanied with alteration of the movements of the ribs in respiration), laryngismus stridulus is present, though Mr. Snow considered the sudden stop in the inspiration as voluntary.* Since I first published an account of that deformity, I have seen numerous cases which convinced me that it is often the cause of laryngismus stridulus, and that many of the infants so deformed are cut off by one of the paroxysms of dyspnoea.

$$
\begin{gathered}
\text { Artillery-place, City-road, } \\
\text { July 16, } 1842 .
\end{gathered}
$$

* See Lancer, No. 916. Mr. Snow was the first also to point out that in these children the abdomen is always enlarged, a fact I ought to have noticed when I wrote on the deformity, though I am persuaded, that gentleman was in error in attributing the altered form of the chest to enlargement of the abdomen: the latter enlarges because, from the abnormal movement of the ribs, the abdominal muscles lose their fixed point of action. 